\title{
COMPARISON OF DT\& GBDT ALGORITHMS FOR PREDICTIVE MODELING OF CURRENCY EXCHANGE RATES
}

\author{
Maan Y. Anad Alsaleem \\ Directorate of Education in Nineveh \\ Tenahî, Duhok, Ramy Land B9, Iraq \\ Maanyounis1983@gmail.com \\ Safwan O. Hasoon \\ College of Computer Science and Mathematics \\ Mosul University \\ Almajmoa, Mosul, Ninavah, Iraq, 41002 \\ Dr.safwan1971@uomosul.edu.iq
}

\begin{abstract}
Recently, many uses of artificial intelligence have appeared in the commercial field. Artificial intelligence allows computers to analyze very large amounts of information and data, reach logical conclusions on many important topics, and make difficult decisions, this will help consumers and businesses make better decisions to improve their lives, and it will also help startups and small companies achieve great long-term success. Currency exchange rates are important matters for both governments, companies, banks and consumers. The decision tree is one of the most widely artificial intelligence tools used in data mining. With the development of this field the decision tree and Gradient boosting decision tree are used to predicate through constructed intelligent predictive system based on it. These algorithms have been used in many stock market forecasting systems based on global market data. The Iraqi dinar exchange rates for the US dollar are affected in local markets, depending on the exchange rate of the Central Bank of Iraq and the features of that auction. The proposed system is used to predict the dollar exchange rates in the Iraq markets Depending on the daily auction data of the Central Bank of Iraq (CBI). The decision tree and Gradient boosting decision tree was trained and testing using dataset of three-year issued by the CBI and compare the performance of both algorithms and find the correlation between the data. (Runtime, accuracy and correlation) criteria are adopted to select the best methods. In system, the characteristic of artificial intelligence have been integrated with the characteristic of data mining to solve problems facing organization to use available data for decision making and multi-source data linking, to provide a unified and integrated view of organization data.
\end{abstract}

Keywords: decision trees, gradient boosting decision tree, correlation, accuracy, run times, exchange rates.

DOI: $10.21303 / 2461-4262.2020 .001132$

\section{Introduction}

The increases use of data in digital form and databases in a wide range in different fields led to the large quantity of these data, it was necessary to develop tools and algorithms to help extract information from these data and find useful information. Therefore new field in artificial intelligence, called data mining, it has emerged as a technique aimed for extracting knowledge [1]. This technique has become more popular in the information age through the exploration of large quantities of data using the techniques of (Pattern Recognition, integration of mathematical methods and statistical information technology) led to possibilities to predict future behavior that helps in decision-making. One method widely used in data mining is Decision trees which is one of the methods used for the purpose of classification and finding a regression to predict the value of a variable object In addition a more accurate prediction method was proposed [2, 3], in this paper introduced view of boosting algorithm as iterative functional gradient descent algorithms. To improve machine learning methods at an acceptable cost for increased learning and accuracy of results in Decision trees. The proposed system is used gradient boosting decision tree (GBDT) as a way to predict the exchange rates of dollar based on the CBI's annual reports of auction daily auction price, quantity and cash for the market price and comparison results for the use of decision trees. 


\section{Decision Tree (DT)}

It is one of the most popular machine learning algorithms and has been widely used in various modern machine learning and data mining applications [4]. General structure consist of root, branches and leaves typically upside down the leaves are at the bottom. There are two main type of it Classification tree and used depends on the desired results of the algorithm. The tree is built in the same way as building ID3 where the contract is chosen based on the concept of entropy which is based on the following equation:

$$
\operatorname{Entropy}(t)=-\sum_{i=0}^{c-1} p(i \mid t) \log _{2} p(i \mid t),
$$

where $c$ is the number of class and $p(i \mid t)$ Indicates the probability of records belonging to that class.

\section{Gradient boosting decision tree}

It is method used to produce a strong learner and data mining applications [5]. Let $\boldsymbol{x} i \in R$ is the dataset and have $n$ examples, $m$ features and $k$ ensemble learning, what want to predict is $y(x)^{k}$. The output of this method is the sum of the prediction values of these trees Using the following equation [6].

$$
y(x)^{k}=\sum_{i=1}^{k} f(x)
$$

where $f$ is output of regression tree.

\section{Implementation and Result}

Proposed System was based on data published by the Central Bank of Iraq for the daily auction of dollars for the years (2015-2016-2017), respectively, which amounted to 479 auction sessions after the deletion of the holidays where there is no auction. As these indicators reflect the comprehensive views of currency exchange rates at the official auction price, market price and quantity offered. The algorithms (GBDT)\&(DT) was adopted to predict the market price and compare the result for the same data. The steps of workflow as show in Fig. 1.

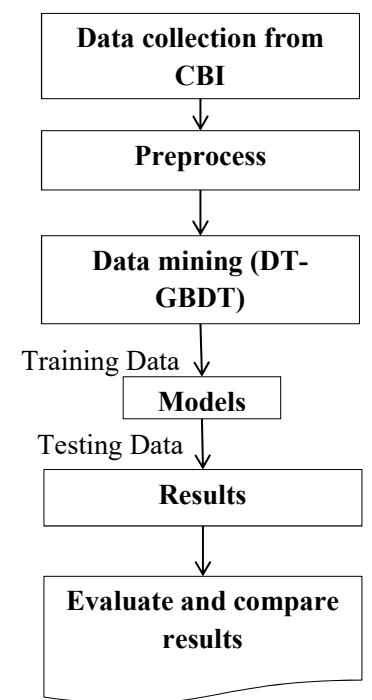

Fig. 1. Proposed Frame Work

The result of two methods were compared for selected the best technique to apply for predictively of proposed system. 


\section{1. Data collection}

At this stage was adopted data of the Central Bank of Iraq, which published on its official site for the years (2015-2016-2017), Table 1. Available on the site https://www.cbi.iq/.

Table 1

A subset of the year dataset

\begin{tabular}{ccccccc}
\hline No. Session & Date & MarketPrice & AuctionPrice & Volume & Cash & Credits \\
\hline 2924 & 06-Apr & 1,292 & 1,166 & $119,020,000$ & $12,200,000$ & $106,820,000$ \\
2925 & 07-Apr & 1,292 & 1,166 & $108,540,000$ & $14,950,000$ & $93,590,000$ \\
2926 & 08-Apr & 1,321 & 1,166 & $116,044,000$ & $15,050,000$ & $100,994,000$ \\
2927 & 09-Apr & 1,327 & 1,166 & $104,770,000$ & $10,650,000$ & $94,120,000$ \\
2928 & $12-\mathrm{Apr}$ & 1,302 & 1,166 & $161,241,189$ & $34,200,000$ & $127,041,189$ \\
2929 & $13-\mathrm{Apr}$ & 1,297 & 1,166 & $165,852,225$ & $38,475,000$ & $127,377,225$ \\
2930 & $14-\mathrm{Apr}$ & 1,297 & 1,166 & $117,789,137$ & $11,800,000$ & $105,989,137$ \\
2931 & 15-Apr & 1,297 & 1,166 & $110,948,963$ & $36,500,000$ & $74,448,963$ \\
2932 & $16-\mathrm{Apr}$ & 1,290 & 1,166 & $140,522,917$ & $32,100,000$ & $108,422,917$ \\
2933 & $19-\mathrm{Apr}$ & 1,295 & 1,166 & $126,470,740$ & $28,850,000$ & $97,620,740$
\end{tabular}

\section{2. Preprocess}

In preprocess the configure of data should be standardizing by applying normalization , delete the empty and duplicate values for fields of various years adopted and converting these into a formula (CSV) dataset for use in data mining.

\section{3. Data mining (DT-GBDT)}

An exploration program was applied using both methods (DT),(GBDT) on the same dataset, which was configured to measure execution time and accuracy of results to make comparison between two method and choses the best depended on.

The results of this research are divided into two sections, first that commercial price forecast and a second that includes comparing the performance of two algorithms for these data.

As a result of the market price of the dollar for the Iraqi dinar for the data approved were according as showing in Fig. 2.

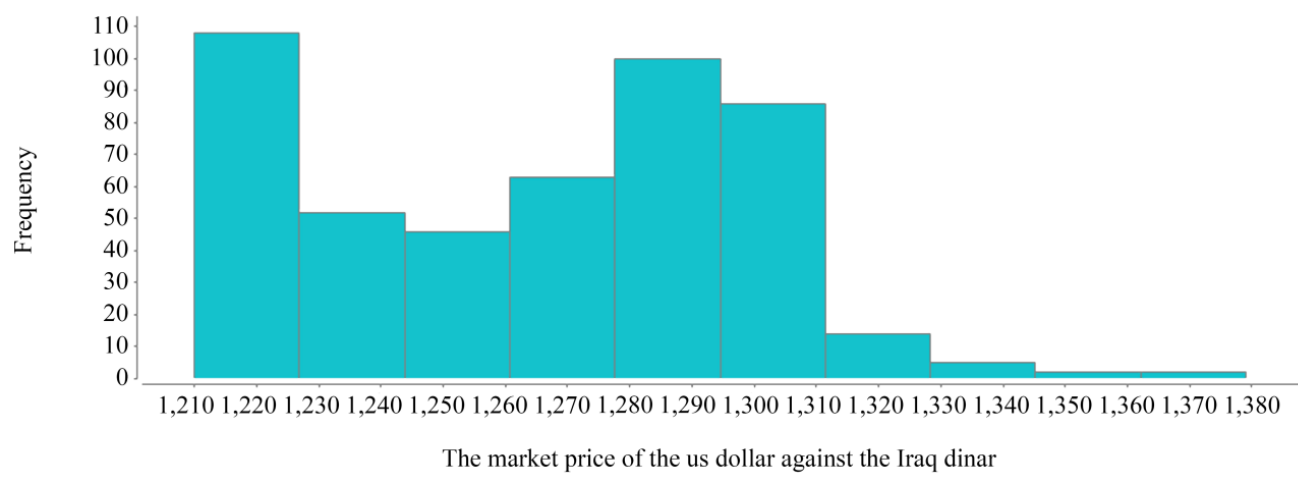

Fig. 2. A diagram of the process

As shown in the Fig. 2, the trade exchange rate of the US dollar compared to the Iraqi dinar for the sample of the research is 1264.985 . 


\section{4. Correlation}

Correlation is a statistical term that refers in general use to the proximity of the two variables and relationship with each other [7-15]. The correlation between fields and their effects as showing in Table 2.

Table 2

The correlation table between the fields

\begin{tabular}{cccccc}
\hline Attribute & Auction price & Cash & Credits & Market price & Volume \\
\hline Auction price & 1 & -0.276 & -0.711 & 0.255 & -0.581 \\
Cash & -0.276 & 1 & 0.407 & -0.089 & 0.580 \\
Credits & -0.711 & 0.407 & 1 & -0.535 & 0.867 \\
Market price & 0.255 & -0.089 & -0.089 & 1 & -0.365 \\
Volume & -0.581 & 0.867 & 0.867 & -0.365 & 1
\end{tabular}

The weights of each fields used as shown in Fig. 3.
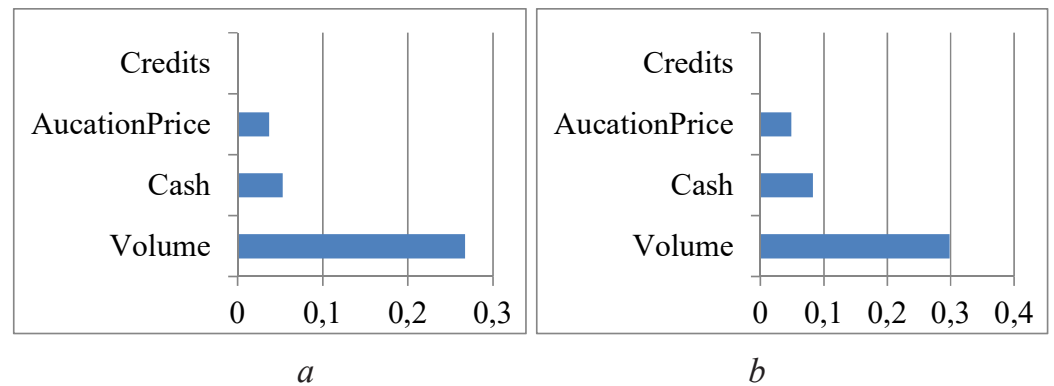

Fig. 3. Weights of each field: $a-\mathrm{DT} ; b-\mathrm{GBDT}$

Runtimes is the time consumed for each algorithm used for prediction is shown in Fig. 4.

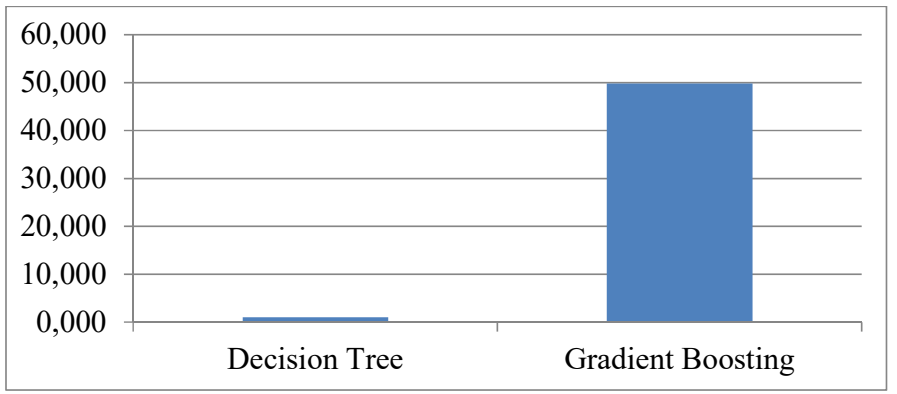

Fig. 4. Runtimes (MS)

From Fig. 4 let's note that the time consumed for GBDT is more than the DT because GBDT is generates several sub-trees and calculates the sum of the main tree and sub-trees. These processes can't be implemented in parallel to reduce the runtime Because of the serial operations that the algorithm calculates.

\section{5. Prediction of DT \& GBDT}

The prediction chart is one of important tools that give visibility to the distribution of the samples and the predictive values as shown in Fig. 5, 6, Table 3. 


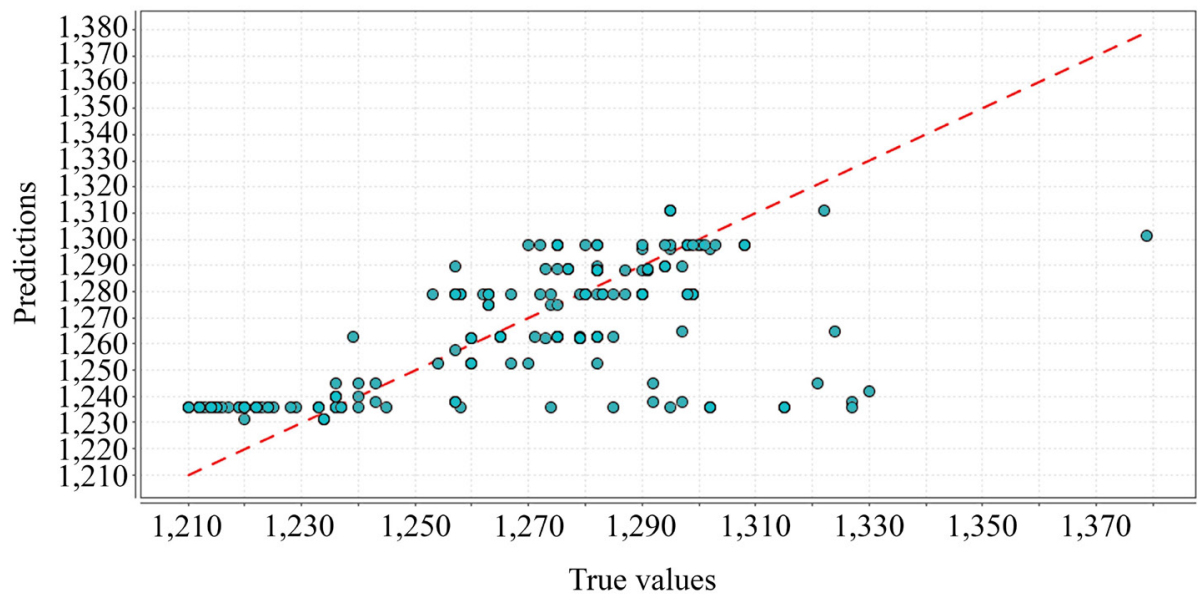

Fig. 5. Prediction chart of DT

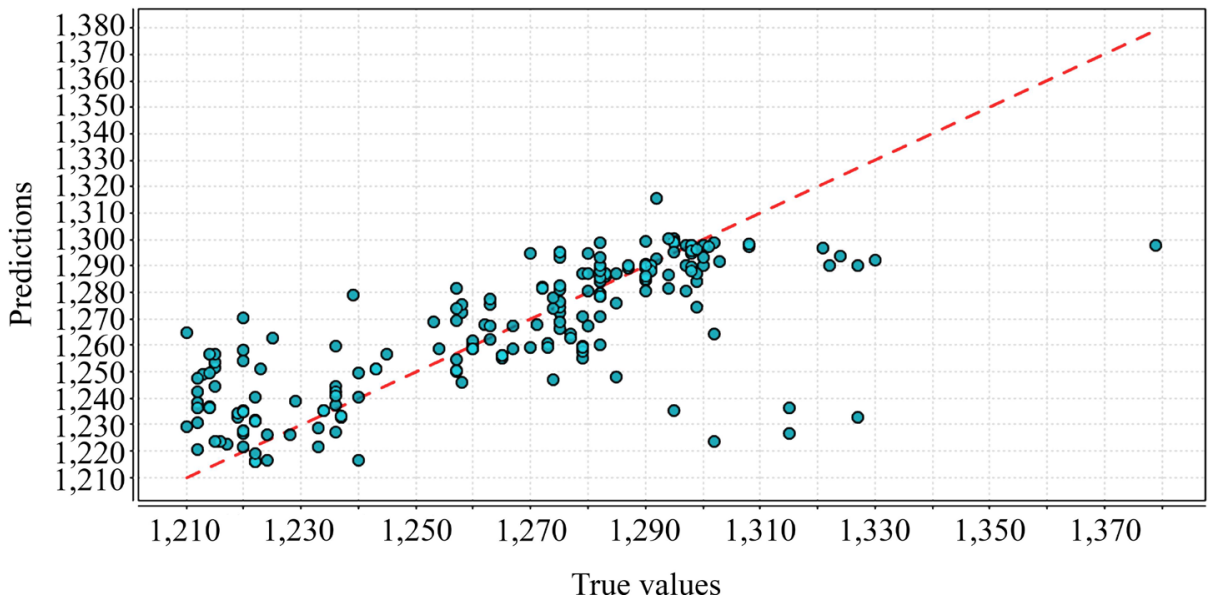

Fig. 6. Prediction chart of GBDT

Table 3

Comparison of error ratio

\begin{tabular}{ccc}
\hline & Gradient Boosting Trees & Decision tree \\
\hline Root mean squared error & $22.078+/-1.167$ (micro average: $22.106+/-0.000)$ & $23.608+/-1.873$ (micro average: $23.667+/-0.000)$ \\
Absolute error & $14.645+/-0.828$ (micro average: $14.636+/-16.568)$ & $16.349+/-1.459$ (micro average: $16.354+/-17.107)$ \\
Relative error lenient & $1.14 \%+/-0.06 \%$ (micro average: $1.14 \%+/-1.27 \%$ ) & $1.28 \%+/-0.12 \%$ (micro average: $1.28 \%+/-1.30 \%)$ \\
Squared error & $488.546+/-51.614$ & $560.157+/-87.500$ \\
Correlation & $($ micro average: $488.697+/-1197.970)$ & $($ micro average: $560.112+/-1286.439)$ \\
& $0.744+/-0.039$ (micro average: 0.736$)$ & $0.693+/-0.087$ (micro average: 0.692$)$
\end{tabular}

\section{Conclusion}

The integration of intelligent techniques and data mining of prosed system is used for predicting currency rates based on bank records of exchange rates, which reflected the result in terms of time and accuracy compared with traditional methods. The DT and GBDT are good tools for decision making to predicate currency rate taking in consideration the DT is a best method to compare with GBDT in term of time (Fig. 3), on the other hand the GBDT is best methods in term of accuracy see Table 3. 


\section{References}

[1] Koncz, K., Hilovská, S. P. (2012). Application of Artificial Intelligence and Data Mining Techniques to Financial Markets. Acta všfs, 6, 62-76.

[2] Friedman, J. H. (2001). Greedy function approximation: A gradient boosting machine. Annals of Statistics, 29 (5), $1189-1232$. doi: http://doi.org/10.1214/aos/1013203451

[3] Friedman, J. H. (2002). Stochastic gradient boosting. Computational Statistics \& Data Analysis, 38 (4), 367-378. doi: http:// doi.org/10.1016/s0167-9473(01)00065-2

[4] Gupta, B., Rawat, A., Jain, A., Arora, A., Dhami, N. (2017). Analysis of Various Decision Tree Algorithms for Classification in Data Mining. International Journal of Computer Applications, 163 (8), 15-19. doi: http://doi.org/10.5120/ijca2017913660

[5] Feng, Z., Xu, C., Tao, D. (2018). Historical Gradient Boosting Machine. EPiC Series in Computing, 55, 68-80. doi: http:// doi.org/10.29007/2sdc

[6] Anghel, A., Papandreou, N., Parnell, T., Palma, De. A., Pozidis, H. (2018). Benchmarking and Optimization of Gradient Boosting Decision Tree Algorithms. Available at: https://arxiv.org/abs/1809.04559

[7] Mu, Y., Liu, X., Wang, L. (2018). A Pearson's correlation coefficient based decision tree and its parallel implementation. Information Sciences, 435, 40-58. doi: http://doi.org/10.1016/j.ins.2017.12.059

[8] Guolin, K., Qi, M. et. al. (2017). LightGBM: A highly efficient gradient boosting decision tree. NIPS, 3149-3157.

[9] Frenkel, J. A.; Bilson, J. F. O., Marston, R. C. (Eds.) (1984). Tests of Monetary and Portfolio Balance Models of Exchange Rate Determination. Exchange Rate Theory and Practise. Chicago: University of Chicago Press, 239-260.

[10] Gençay, R. (1999). Linear, non-linear and essential foreign exchange rate prediction with simple technical trading rules. Journal of International Economics, 47 (1), 91-107. doi: http://doi.org/10.1016/s0022-1996(98)00017-8

[11] Béreau, S., Villavicencio, A. L., Mignon, V. (2010). Nonlinear adjustment of the real exchange rate towards its equilibrium value: A panel smooth transition error correction modelling. Economic Modelling, 27 (1), 404-416. doi: http://doi.org/10.1016/ j.econmod.2009.10.007

[12] Wong, W. K., Xia, M., Chu, W. C. (2010). Adaptive neural network model for time-series forecasting. European Journal of Operational Research, 207 (2), 807-816. doi: http://doi.org/10.1016/j.ejor.2010.05.022

[13] Anders, U., Hann, T. H., Nakaheizadeh, G.; Weigend, A. S., Abu-Mustafa, Y., Refens, A. P. N. (Eds.) (1997). Testing for Nonlinearity with Neural Networks. Decision Technologies for Financial Engineering. Singapore: World Scientific.

[14] Low, A. H. W., Muthuswamy, J.; Dunis, C. (Ed.) (1996). Information Flows in High Frequency Exchange Rates., Forecasting Financial Markets. Exchange Rates and Asset Management. Chichester: John Wiley \& Sons.

[15] Lemeshko, O., Yevdokymenko, M., Anad Alsaleem, N. Y. (2018). Development of the tensor model of multipath qoe-routing in an infocommunication network with providing the required quality rating. Eastern-European Journal of Enterprise Technologies, 5 (2 (95)), 40-46. doi: http://doi.org/10.15587/1729-4061.2018.141989

Received date 15.12.2019

Accepted date 24.01.2020

Published date 31.01.2020
(C) The Author(s) 2020

This is an open access article under the CC BY license (http://creativecommons.org/licenses/by/4.0). 